\title{
Cracking the system
}

I took a moment to listen to his breathing. My heart sank. Even without the aid of a stethoscope, it sounded like stridor and, given his age and past smoking, a bronchial carcinoma until proven otherwise.

It had not been an easy trip for my Dad who, accompanied by Mum, had fallen through the system when their first connecting flight from Glasgow had been delayed. It subsequently took them five flights and over 48 hours to reach Los Angeles. They had come to visit me while I was on a year's Harkness Fellowship studying approaches to improve healthcare quality. Back in the UK, I worked a day per week as a GP as part of an academic post and didn't consider myself an especially astute physician compared with my more experienced peers. But I am wary of the dangers of inappropriate medicalisation, especially having spent a good deal of time in the past trying to protect Dad from the medical system. l'd failed to avert him from the literal treadmill of cardiac investigation for what l'd always strongly suspected to be psychologically-related chest pain. $\mathrm{He}$ presently appeared to have stridor and breathlessness on fairly minimal exertion. $\mathrm{He}$ had seen his own family doctor twice in the past 3 months and initially been prescribed an inhaler for 'bronchitis.' I might have done something similar myself.

Now he was thousands of miles away from our cherished British NHS. I knew the NHS wasn't perfect. I once sat next to an American attending a healthcare organisation conference in the UK. Following presentation after presentation on organisational problems within the NHS, he turned to me in amazement: 'Hey - I thought you guys loved the NHS. I never knew it was such a mess!' But the NHS works well on the whole and we British are generally ideologically wedded to 'socialised' health care. Like unrepentant abusers, we know its okay to beat up the one we love because it will always be there for us.

Dads' symptoms also seemed to have worsened during his journey. I could have got him checked out in the US - and run the gauntlet of making a claim on his travel insurance with its attendant complexities and financial catches. The alternative was to wait until he returned to the UK 3 weeks later - but have the risk of a medical emergency trapping him in the US. We were all also due to go camping overnight with my son's cub pack. Fortuitously, we found a family physician with a stethoscope to hand at camp that afternoon. He checked Dad and reassured me, in the relative privacy of our tent, that I had been the anxious medical son who had temporarily mislaid objectivity.

I travelled to Minnesota 2 days later with a clear conscience. I was interviewing people from HealthPartners (a partially integrated, not-for-profit managed care system) about their efforts to improve quality of care. Within the first couple of interviews l'd already picked up consistent messages about their efforts to 'systemise' patient care. Their shared goal was to create the right sort of culture and conditions for physicians and other healthcare workers 'where it is easier to do the right than the wrong thing.' I dutifully nodded and facilitated whenever interviewees espoused the importance of putting the needs of their members first. Repeated exposures to similar policy messages in the UK had immunised me against the rhetoric of patient-centredness.

Meanwhile, back in Los Angeles, Dad's symptoms were not abating and he consulted another of our medical friends. When I got back 3 days later, he had seen a family physician, an otolaryngologist, and undergone a chest $\mathrm{X}$-ray and flexible laryngoscopy. The diagnosis was initially considered to be infective but a CT scan was recommended when he got back to the UK to exclude malignancy. When he failed to respond to his prescribed steroids 2 days later, our family physician friend recommended his urgent return to the UK for further investigation. I then spent the weekend negotiating with his travel insurance company, warily trying to anticipate any unforeseen clauses that could lead to the denial of his claim.
Things worked out and everyone was relieved when he got back to the UK and into the reliable and uncomplicated arms of the NHS. This expectation was supported by a recent Commonwealth Fund report, in which UK health care was ranked first for overall performance and first for quality of care among six industrialised countries compared with the US ranking of last and fifth respectively. ${ }^{1}$ Armed with the results of his initial consultations, Dad could see his usual family physician and be referred to a specialist under the '2-week rule' for any suspected malignancy. According to the National Institute for Health and Clinical Excellence (NICE) guideline on lung cancer, stridor merits an urgent referral to a chest physician, even given a normal chest $\mathrm{X}$-ray. ${ }^{2}$

\section{THINGS THAT GO BUMP IN THE SYSTEM}

Then things stopped going as planned. Dad's usual GP didn't think it was stridor and mentioned how he had once had 'real' stridor when some food got lodged in his windpipe. He re-enacted this episode by clutching his own throat and gasping. In fairness, traditional medical education has tended to promulgate recognition of 'classical' and, in this case, life-threatening presentations rather than evolving clinical signs that GPs may encounter during earlier, less distinct stages. Fortunately, Dad was able to trump tradition by producing a letter from his US family physician. He was then referred under the 2-week rule - but to another otolaryngologist rather than a chest physician.

The otolaryngologist he consulted agreed that a chest opinion was needed - but that there would be some delay in his own report going to the chest physician because of a long weekend holiday. (Perhaps all the telephones were on holiday too). Left in the no-man's land of not knowing when he might be seen next, and feeling more uncomfortable a couple of days later, Dad attended his local hospital emergency department.

He was initially greeted with irritation 
before receiving a more sympathetic hearing and a further course of steroids. Two days later, still in limbo, he consulted the 'out-ofhours' primary care service. The understanding GP arranged an informal appointment for him with a (third) otolaryngologist the next day. This specialist explained that although a CT scan was indicated, the local scanner had just been repaired. Dad could either queue behind more urgent cases or, if he was concerned enough, pay around $£ 500$ for a scan at a private hospital. After making some enquiries and finding out that the scan would cost $£ 700$, Dad trundled back to his family physician for the necessary referral.

As his usual GP was unavailable, he saw another in the practice instead. This GP listened to the whole story and organised some basic non-invasive tests (to exclude a cardiac cause for breathlessness) before arranging hospital admission for definitive investigation by a chest physician. Things were now back on track.

Bronchoscopy subsequently revealed a mass in Dad's left main bronchus which histology confirmed as a squamous cell carcinoma. The long-awaited CT scan suggested it might be operable. Dad was admitted a few days later to a more distant specialist hospital. The surgeon there performed a further evaluative bronchoscopy and also sheared off some tumour by laser.

Post-operatively, his distress and discomfort prompted Mum to request pain control. Next followed a week of anxiety during which Dad remained in the ward waiting to see the surgeon, who was tied up elsewhere. The surgeon got to them just before the weekend and broke the news that the cancer was inoperable.

After a 10-day wait in the now familiar noman's land, Dad met with the oncologist who offered a 4-week course of radical radiotherapy. He subsequently underwent 20 daily radiotherapy treatments, each entailing a 50-mile round trip.

There were no places available on the 'accelerated' radiotherapy programme. The accelerated treatment concentrates the 20 treatments into five in-patient days and increases average 2-year survival from $24 \%$ to $37 \%$ compared with conventional radiotherapy. ${ }^{2}$ I don't know if they tell the patients that.

\section{THE NEED FOR JOINED-UP QUALITY IMPROVEMENT}

So why did things go wrong? One selfevident explanation is that 'the system' did not work as reliably as it should have. Like dogged Vegas gamblers, healthcare leaders and researchers have been trying to crack 'the system' for years. Repeated dashes for better quality health care have spawned an abundance of Big Ideas. One such idea I was working with and applying to US healthcare systems is the 'multi-level framework.' This framework suggests that significant progress in quality improvement depends upon launching and coordinating a range of efforts across all levels of healthcare systems (individual, clinical teams, organisational, wider system, or environment). ${ }^{3}$ It implies that improvement efforts at each level are necessary but not always sufficient to achieve meaningful progress.

This relatively parsimonious multilevel framework provides one lens to examine how some of Dad's less memorable experiences could have been averted or ameliorated. At the individual level, targeted training and decision-support might have helped the first family physician recognise stridor and ensure timely referral to the most appropriate specialist first time in line with the NICE guideline. At the team level, Dad needed better coordination among the various individuals in primary and secondary care to ensure an earlier consultation with a respiratory physician. At the organisational level, better access to CT scanning facilities would have meant that Dad was not forced into either shelling out for a (clinically indicated) private CT or waiting for one on the NHS. It might also have been reasonable to expect a standard procedure for ensuring pain control following bronchoscopic laser treatment or a shorter hospital stay while waiting for the final opinion from the surgeon. Dad's experience of an interminable wait to start radical radiotherapy is corroborated by the aforementioned survey on performance: while the US ranks sixth on access to health care, the UK comes little better at fourth. A 2005 audit by the Royal College of Radiologists found that over half of patients needing radical radiotherapy waited longer than the maximum acceptable delay of 4 weeks from the point of diagnosis. ${ }^{4}$ The more clinically effective form of accelerated radiotherapy could have been available, and even if a waiting list was absolutely necessary, the criteria used to prioritise cases made explicit.

The folks in Minnesota might justifiably look on with wry smiles. The only sense of systemisation from this account is one of systemised failures and delays, with individuals either shuffling uncertainly at the borders of their own known worlds or battling to overcome unreliability and organisational inertia. These failures to provide 'joined-up' health care are rooted in the lack of joined-up quality improvement across all levels of the healthcare system.

I have since returned to general practice in the UK with a heightened awareness of my own limitations and those of the system our patients need to navigate. Whatever deficits persist in my clinical acumen, I hope to be sensitised to the need for advocacy and watch out for those patients who trundle around the margins of the healthcare system, victims of systematic unfairness or failures. However, significant and sustainable change for the better should require neither professional heroics nor martyrdom - but joined-up, multilevel quality improvement focused around the patient experience.

\section{Robbie Foy}

\section{Acknowledgements}

I thank Brian Mittman, Leif Solberg, and Mark Lambert for their comments on an earlier version of this piece. Robbie Foy's Harknes Fellowship was funded by the Commonwealth Fund and the Health Foundation. The views represented here are those of the author and not the funding bodies.

\section{REFERENCES}

1. Davis K, Schoen C, Schoenbaum SC, et al. Mirror mirror on the wall: an international update on the comparative performance of American health care. New York: The Commonwealth Fund, 2007.

2. National Institute for Health and Clinical Excellence. Lung cancer: diagnosis and treatment. London: NICE, 2005.

3. Ferlie EB, Shortell SM. Improving the quality of health care in the United Kingdom and the United States: a framework for change. Milbank Q 2001; 79(2): 281-315

4. Leatherman S, Sutherland K. Patient and public experience in the NHS. Quest for quality and improved performance. London: The Health Foundation, 2007.

DOI: 10.3399/bjgp08X342462 